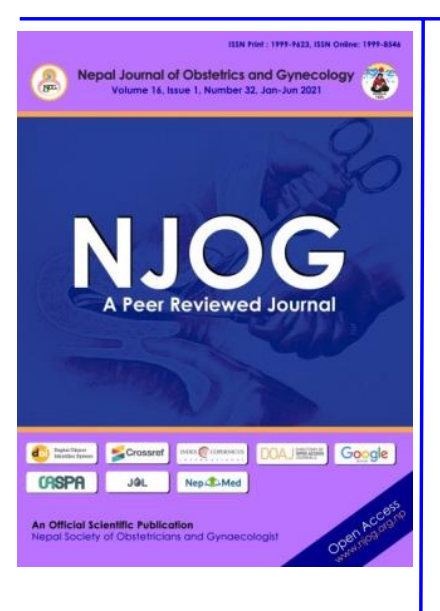

\section{CORRESPONDENCE}

Dr Sandesh Poudel

Paropakar Maternity and Women's Hospital, Thapathali, Kathmandu, Nepal

Email: sandeshjyotipoudel@ gmail.com;

Phone: +977-9851064246

Received: April 15, 2020

Accepted: May 1, 2021

\section{Citation:}

Poudel S, Dangal G. Clinical outcome of sacrospinous fixation following pelvic organ prolapse surgery. Nep J Obstet Gynecol. 2021;16(32):8184. DOI: https:// doi.org/10.3126/ njog.v16i1.37610

\title{
Clinical outcome of sacrospinous fixation following pelvic organ prolapse surgery
}

\author{
Sandesh Poudel ${ }^{1}$, Ganesh Dangal ${ }^{2}$ \\ ${ }^{1}$ Paropakar Maternity and Women's Hospital, Thapathali, Kathmandu. \\ ${ }^{2}$ Kathmandu Model Hospital, Red Cross Marg, Kathmandu.
}

\section{ABSTRACT}

Aims: To evaluate the midterm outcome of sacrospinous fixation done during surgical management of pelvic organ prolapse.

Methods: This was an interview based cross sectional follow up study done among the patients who underwent sacrospinous fixation procedure along with pelvic organ prolapse surgery in Kathmandu Model Hospital and Paropakar Maternity Hospital. This was conducted between $15^{\text {th }}$ February 2021 and $15^{\text {th }}$ April 2021. Post-operative cases 22 to 30 months (average 2 years) from the day of surgery were included.

Results: Out of 321 eligible SSF patients from both the hospital, 156 agreed to participate. Among them, 77 (48\%) were in $60-69$ years of age and $82 \%$ were postmenopausal; $33 \%$ were more than para $3 ; 20 \%$ had right gluteal pain that was decreased to $1.9 \%$ by 2 years; and $20 \%$ had some degree of urgency and stress incontinence.

Conclusion: Sacrospinous fixation is safe and effective procedure which can be done during pelvic organ prolapse surgery with good success rate and minimal post-operative complications.

Keywords: fixation, follow up, pelvic organ prolapse, sacrospinous

\section{INTRODUCTION}

Pelvic organ prolapse, a highly prevalent pelvic floor disorder in female, is defined as a descent of vaginal walls and/or uterus towards or through the vaginal opening thus adversely affecting women's quality of life and sexual function. The prevalence of pelvic organ prolapse (POP) reaches 3 to $6 \%$ when defined by symptoms and up to even $50 \%$ by vaginal examination. ${ }^{1}$ With overall prevalence of 10 percent among Nepalese reproductive age group, this has been one of the major reproductive health issue affecting all age groups, ethnic castes and from all ecological regions particularly in rural area. ${ }^{2}$

Surgical treatment remains the mainstay of POP therapy which aims not only to cure the present problem but also prevents recurrence which is seen in 0.2 to $12.8 \%$ of the subjects. The incidence of vault prolapse after hysterectomy is uncertain but appears to be increased fivefold after vaginal hysterectomy. ${ }^{3}$
Among various surgical techniques defined to prevent recurrence, sacrospinous fixation (SSF) during POP surgery is the procedure which has advantages, including success rates comparable to abdominal procedures, the ability to repair concomitant pelvic floor defects, no need of laparotomy, shorter hospital stays, and the preservation of vaginal length and coital function. ${ }^{4}$ The most common problem after this procedure is thehigh rate of postoperative cystocele in the follow up period, which ap- proaches to $37 \%$ resulting from the deviation of the vaginal axis. ${ }^{5}$ Other postoperative problems include uri-nary symptoms, buttock pain and dyspareunia due to vaginal narrow- ing and alteration of vaginal axis be- side immediate complications like hemorrhage and injury to bladderand rectum.

This study is aimed at evaluating the outcome of the sacrospinous fixation and complications with respect to descent of vagina, urinary or rectal symptoms, sexual functions and overall satisfaction of the procedure. 


\section{METHODS}

This was an interview based cross sectional study done among the patients who underwent sacrospinous fixation procedure along with POP surgery to prevent or treat vault prolapse in Kathmandu Model Hospital and Paropakar Maternity Hospital in Kathmandu. Ethical approvals were taken. Study tool was approved by IRCs. Patients with sacrospinous fixation during vaginal hysterectomy or vault repair who reach 22 to 30 months from the day of surgery during the period of data collection were included in the study. Records of the eligible patients were reviewed and interviewed over the telephone whoever agreed to participate. The interview was conducted between $15^{\text {th }}$ February 2021 and $15^{\text {th }}$ April 2021. Conversations between the patients and the interviewer were recorded with verbal consent and stored. Demographic and clinical profile were recorded from the inpatient charts while midterm postsurgical problems of vaginal bulge, urinary symptoms, sexual functions, buttock or back pain and overall satisfaction were evaluated as primary outcome of the study from the telephonic interview. Recorded data were analyzed using SPSS 21 software.

The surgical technique of SSF employed in both the hospital were similar where vaginal vault was fixed

onto the right sacrospinous ligament using blunt digital dissection of the ipsilateral ischiorectal fossa with an approach via the posterior vaginal compartment. Two No 1 polydiaxanone sutures (PDS 1) were placed on the right sacrospinous ligament by means of Deschamps ligature carrier and anchored with the vaginal vault. In case of sacrospinous hysteropexy sutures were anchored over the cervix in the stroma of the posterior wall.

\section{RESULTS}

Out of 321 eligible SSF patients from both the hospital, 156 patients were eligible for interiew over the phone. Among 156 patients enrolled, 77 (48\%) of women were in 60-69 years of age and $82 \%$ were postmenopausal while maximum number of patients were more than para $3(33 \%)$. [Table-1]

Table-1: Distribution by age, menstrual status and parity $(\mathrm{N}=156]$

\begin{tabular}{cll}
\hline & Variables & Frequency $(\%)$ \\
\hline & $40-49$ & $15(9.6 \%)$ \\
Age & $50-59$ & $37(23.7 \%)$ \\
(years) & $60-69$ & $77(49.3 \%)$ \\
& $70-79$ & $27(17.3 \%)$ \\
Menstrual & Premenopause & $28(18 \%)$ \\
Status & Postmenopause & $128(82 \%)$ \\
& P1 & $31(19.8 \%)$ \\
Parity & P2 & $37(23.7 \%)$ \\
& P3 & $34(21.7 \%)$ \\
& $>$ P3 & $52(33.3 \%)$ \\
\hline
\end{tabular}

Majority (93\%) of cases undergoing SSF had prolapse surgery with vaginal hysterectomy. [Table-2]

Table-2: Procedures performed along with SSF $[\mathrm{N}=156]$

\begin{tabular}{lc}
\hline Procedure & Number (\%) \\
\hline Vaginal Hysterectomy with SSF & $145(93 \%)$ \\
SSF for vault prolapse & $8(5 \%)$ \\
Sacrospinous Hysteropexy & $3(2 \%)$
\end{tabular}

Immediate post-operative complications recorded in medical records were that were buttock pain and urinary retention. Buttock pain was managed with oral analgesics; urinary retention by Foleys catheterization for few days along with treatment of urinary tract infection; and vault infection by broad spectrum antibiotics. All the enrolled patients were discharged within 10 days of surgery. [Table-3]

Table-3: Immediate postoperative complications after sacrospinous fixation $(\mathrm{N}=28)$

\begin{tabular}{lc}
\hline Immediate complications & Frequency $(\%)$ \\
\hline Right Buttock Pain & $20(72 \%)$ \\
Urinary Retention & $5(18 \%)$ \\
Vault Infection & $2(7 \%)$ \\
Hemorrhage requiring blood trans- & $1((3 \%)$ \\
fusion & \\
\hline
\end{tabular}

During 22 to 30 months follow up (mean follow up of 2 year) of the patients based on the telephonic conversation, $98 \%$ of the patients were satisfied with their surgeries citing improvement in their quality of life while 2 patients were discontented due to recurrence of vaginal bulge and worsening of urinary symptoms. $23(14.7 \%)$ had some form of recurrence of vaginal bulge not requiring immediate medical attention while one patient felt that she needs repeat surgical intervention. 93\% of the patients who had right buttock pain postoperatively were symptom free within 3 months of surgery while 3 patients still complained of discomfort and occasional pain didn't require medical attention. $20 \%$ complained of lower urinary tract symptoms (LUTS) like urge incontinence and stress incontinence but only one reported as bothersome. [Table $-4]$

Table-4: Late complications at 2 year of sacrospinous fixation surgery $(\mathrm{N}=65)$

\begin{tabular}{ll}
\hline Complications & Number \\
\hline Recurrence of vaginal bulge & $24(15.3 \%)$ \\
LUTS & $31(20 \%)$ \\
\multicolumn{1}{c}{ Urge Incontinence } & $23(14.7 \%)$ \\
$\quad$ Stress Incontinence & $8(5.1 \%)$ \\
Dyspareunia & $7(4 \%)$ \\
Occasional Right buttock pain & $3(1.9 \%)$ \\
\hline
\end{tabular}




\section{DISCUSSION}

The current study, at a mean follow up of 2 year, found high percentage of patients (98\%) reporting satisfaction following the SSF procedure. Similar degree of satisfaction after sacrospionous fixation following vaginal hysterectomy was reported by Kumar et $\mathrm{al}^{6}$ while Dietz et $\mathrm{al}^{7}$ reported satisfaction among $84 \%$ of the patients who underwent sacrospinous hysteropexy. Similar results were seen in a study by Aigmueller et $\mathrm{al}^{8}$ during their 2-15 years follow up after surgery.

Various authors have demonstrated the anterior recurrence rate of $8 \%-35 \%$ and posterior recurrence rate of $1 \%-5 \% .^{5,7,8,9}$ The probable explanation, apart from age related weakness of pelvic floor tissues, is the change in the dynamic architecture of the pelvic floor due to posterior displacement of vaginal axis resulting prominently in cystocele. ${ }^{8}$ Similar symptomatic recurrence of vaginal fullness were seen during this 2 year follow up (15.3\%) though exact anatomical displacement were not evaluated in our study.

Three patients in present study had discomfort and occasional pain over right buttock which did not warrant for any treatment. Complaints of gluteal pain which is unique to SSF are mostly seen during immediate postoperative period which in most instances resolved spontaneously within 3 to 6 months with or without analgesics but persisted in some cases. ${ }^{10,11}$ Reported rates of gluteal pain after sacrospinous ligament fixation range from $12-55 \%$ in the immediate postoperative period and from $4-15 \%$ at 4 to 6 weeks postoperatively. The source of gluteal pain often is attributed to injury to the nerve to levator ani or pudendal nerve. ${ }^{12}$ Small number of patients who complains of the persistent severe buttock pain may necessitate the removal of suture as reported by Dangal et al ${ }^{13}$ in their study.

Greisen et $\mathrm{al}^{14}$ reported improvement in urinary frequency and urinary incontinence symptoms following SSF surgery while most studies showed no particular relation of the surgery with the urinary symptoms. $20 \%$ of the respondents in the present study had some lower urinary tract symptoms most of which were not troublesome. The effect of SSF on lower urinary tract function is difficult to determine, as there are multiple contributory factors. Though age, postmenopausal status and parity are the common cumulative contributory factors which are seen in our study, de novo urgency and frequency following any POP surgery cannot be ruled out as reported by Pham et al. ${ }^{15}$ Similarly dyspareunia after SSF as seen in $4 \%$ among sexually active women in our study is consistent with the findings by Lovatsis et $\mathrm{al}^{11}$ who reported dyspareunia in $3.2 \%$ following surgery. Dyspareunia may be attributed to vaginal narrowing. deviation, introital narrowing and age related genital changes.

This study is limited by small number of patients, shorter period of follow up and more importantly it was based only on subjective perception of the symptoms with telephone consultation rather than correlation with clinical findings. As the study was done during COVID 19 pandemic, telephonic consultations seem the equally effective and promising method of evaluation and follow up of selected chronic cases with proper structural setting, although it cannot fully replace face to face conversation and examination. ${ }^{16}$

\section{CONCLUSIONS}

Sacrospinous ligament fixation is a simple, safe and cost effective procedure which can be performed along with vaginal hysterectomy and for treatment of vault prolapse with satisfactory results and minimal long term complications.

\section{ACKNOWLEDGEMENT}

We Acknowledge Paropakar Maternity and Women's Hospital and Kathmandu Model Hospital to facilitate generating the research participants.

\section{REFERENCES}

1. Barber MD, Maher C. Epidemiology and outcome assessment of pelvic organ prolapse. Int Urogynecol J. 2013;24(11):1783-90. URL: https://doi.org/10.1007/s00192-013-2169-9

2. NHTC, UNFPA, Jhpiego. Management of Pelvic Organ Prolapse for Doctors: Reference and Learners' Guide; 2015. Page 21-22. URL: https://nepal.unfpa.org/sites/default/files/pubpdf/POP_Reference_Learner_Guide_Final_ 2015.pdf

3. Barrington JW, Edwards G. Posthysterectomy vault prolapse. Int Urogynecol J Pelvic Floor Dysfunct. 2000;11(4):241-5. URL: https:// doi.org/10.1007/s001920070033

4. Choi KH, Hong JY. Management of pelvic organ prolapse. Korean J Urol. 2014;55(11):693702. URL: https://doi.org/10.4111/ kju.2014.55.11.693

5. Paraiso MF, Ballard LA, Walters MD, Lee JC, Mitchinson AR. Pelvic support defects and visceral and sexual function in women treated with sacrospinous ligament suspension and pelvic reconstruction. Am J Obstet Gynecol. 1996;175 (6):1423-30. URL: https://doi.org/10.1016/ S0002-9378(96)70085-6

6. Kumar R, Kamat L, Shilpa T, Andola S. Sacrospinous ligament fixation for prevention and treatment of vaginal vault prolapse: a retrospective study of 45 cases. Int J Reprod Contracept Obstet Gynecol. 2016;5:4014-7. URL: http:// dx.doi.org/10.18203/2320-1770.jjrcog20163881 
7. Dietz V, de Jong J, Huisman M, Schraffordt Koops S, Heintz P, van der Vaart $\mathrm{H}$. The effectiveness of the sacrospinous hysteropexy for the primary treatment of uterovaginal prolapse. Int Urogynecol J Pelvic Floor Dysfunct. 2007;18(11):1271-6. URL: https://doi.org/10.1007/s00192-007-03366

8. Aigmueller T, Riss P, Dungl A, Bauer H. Longterm follow-up after vaginal sacrospinous fixation: patient satisfaction, anatomical results and quality of life. Int Urogynecol J Pelvic Floor Dysfunct. 2008;19(7):965-9. URL: https:// doi.org/10.1007/s00192-008-0563-5

9. Allahdin S, Herd D, Reid BA. Twenty-five sacrospinous ligament fixation procedures in a district general hospital: our experience. J Obstet Gynaecol. 2005;25(4):361-3. URL: https:// doi.org/10.1080/01443610500118731

10. Petri E, Ashok K. Sacrospinous vaginal fixation --current status. Acta Obstet Gynecol Scand. 2011;90(5):429-36. URL: doi.org/10.1111/j.1600-0412.2011.01084.X

11. Lovatsis D, Drutz HP. Safety and efficacy of sacrospinous vault suspension. Int Urogynecol J Pelvic Floor Dysfunct. 2002;13(5):308-13. URL: https://doi.org/10.1007/s001920200067

12. Florian-Rodriguez ME, Hare A, Chin K, Phelan JN, Ripperda CM, Corton MM. Inferior gluteal and other nerves associated with sacrospinous ligament: a cadaver study. Am J Obstet Gynecol. 2016;215(5):646.e1-646.e6. URL: https:// doi.org/10.1016/j.ajog.2016.06.025
13. Dangal G, Poudel R, Shrestha R, Karki A, Pradhan HK, Bhattachan K, et al. Outcome of Sacrospinous Ligament Fixation of the Vault during Repair of Pelvic Organ Prolapse. J Nepal Health Res Counc. 2018;16(3):321-324. URL: jnhrc.v16i3.1482 http://dx.doi.org/10.33314/

14. Greisen S, Axelsen SM, Bek KM, Guldberg R, Kristensen MG. Fast track sacrospinous ligament fixation: subjective and objective outcomes at 6 months. BMC Women's Health. 2021;21(1):154. URL: https://doi.org/10.1186/ s12905-021-01309-1

15. Pham T, Kenton K, Mueller E, Brubaker L. New pelvic symptoms are common after reconstructive pelvic surgery. Am J Obstet Gynecol. 2009;200(1):88e1. URL: https:// doi.org/10.1016/j.ajog.2008.08.010

16. Hasani SA, Ghafri TA, Al Lawati H, Mohammed J, Al Mukhainai A, Al Ajmi F, et al. The use of Telephone Consultation in Primary Health Care During COVID-19 Pandemic, Oman: Perceptions from Physicians. J Prim Care Com Health. 2020;11:1-8. URL: https:// doi.org/10.1177/2150132720976480 